\title{
Rosuvastatin attenuates contrast-induced nephropathy through modulation of nitric oxide, inflammatory responses, oxidative stress and apoptosis in diabetic male rats
}

\author{
Jie Deng ${ }^{\dagger}$, Guijun $\mathrm{Wu}^{\dagger}$, Chen Yang ${ }^{\dagger}, \mathrm{Yi}$ Li, Quanmin Jing and Yaling Han
}

\begin{abstract}
Background: Contrast-induced nephropathy $(\mathrm{CIN})$ is an important cause of acute renal failure. We observe the effect of rosuvastatin on preventing CIN in diabetic rats in current study.

Methods: Diabetic rats were then divided into five groups: 1 diabetic rats (D), 2 diabetic rats + contrast media (DCM), 3 diabetic rats + rosuvastatin (DR), 4 diabetic rats + contrast media + rosuvastatin (DRCM), 5 non-diabetic rat control (NDCM). Contrast-induced nephropathy was induced by intravenous injection a single dose of indomethacin (10 mg/kg), double doses of N-nitro-L-arginine methyl ester $(10 \mathrm{mg} / \mathrm{kg})$ and a single dose of high-osmolar contrast medium meglumine amidotrizoate $(6 \mathrm{ml} / \mathrm{kg})$. DR and DRCM group rats were treated with rosuvastatin $(10 \mathrm{mg} / \mathrm{kg} /$ day $)$ by gavage for 5 days. At the end of treatment, the experimental groups were sacrificed, and their renal tissues were investigated histopathologically beside assessments of functional activities, nitric oxide metabolites, and oxidative stress and apoptic markers.

Results: After 6 days, serum creatinine and urine microprotein were increased, and creatinine clearance, kidney nitrite were decreased in DCM rats compared with NDCM, D, DR and DRCM groups. Histopathology scores in group DCM were increased compared with groups NDCM, D and DR, but lower in group DRCM than in group DCM $(p<0.01)$. Kidney thiobarbituric acid-reacting substances (TBARS), serum malondialdehyde (MDA), and serum protein carbonyl content (PCC) were increased, and serum thiol was decreased in the DCM group compared with groups NDCM, D and DR; however, these results were reversed in group DRCM compared with group DCM. Both expression of IL-6, TNF-a and the percentage of apoptotic cells were increased in group DCM than in groups NDCM, D and DR, but they were decreased in group DRCM than in group DCM. The expression of phospho-p38, cleaved capase-3, and the Bax/Bcl-2 ratio, were increased in group DCM than in groups NDCM, D and DR, but were decreased in group DRCM than in group DCM.
\end{abstract}

Conclusions: Our study demonstrated that rosuvastatin treatment attenuated both inflammatory processes and apoptosis and inhibited oxidative stress and the p38 MAPK pathway in a diabetic rat model in the setting of CIN.

Keywords: Diabetic, Contrast-induced nephropathy (CIN), Rosuvastatin

\footnotetext{
* Correspondence: D.jie@126.com

${ }^{\dagger}$ Equal contributors

Department of Cardiology, the General Hospital of Shenyang Military Region,

Chinese People's Liberation Army, Shenyang, Liaoing, China
} 


\section{Introduction}

Contrast-induced nephropathy $(\mathrm{CIN})$ is one of important cause of hospital-acquired acute renal failure [1], which is associated with an increase of $25 \%$ or more, or an absolute increase of $0.5 \mathrm{mg} / \mathrm{dl}$ or more in serum creatinine from baseline value, at $48-72 \mathrm{~h}$ following the exposure to contrast media. The incidence of CIN is recognized as a significant contributor to morbidity and mortality in patients receiving coronary angiography and subsequent intervention [2,3]. Diabetes mellitus (DM) is an important risk factors for CIN [4]. In combination with other risk factors, DM aggravates the situation. CIN develops more frequently after administration of contrast media in DM patients than in patients without diabetes [5]. Additionally, diabetic patients with CIN have a significantly decreased survival rate compared with nondiabetic patients [5]. The exact mechanism of CIN has not been cleanly understand. Renal hypoxia, combined with the generation of reactive oxygen species, plays a central role in the pathogenesis of CIN, and the diabetic kidney is particularly susceptible to intensified hypoxic and oxidative stress following the administration of contrast media [6]. The pathophysiology of this vulnerability is complex and involves various mechanisms, including a priori enhanced tubular transport activity, oxygen consumption, and the generation of reactive oxygen species [7].

Dyslipidemia is common in diabetic patients. Typical dyslipidemia of diabetic patients is hypertriglyceridemia, low high-density lipoprotein cholesterol (HDL-C) levels, high small and dense low-density lipoprotein (LDL) particles levels [8]. Most of diabetic patients have complications such as retinopathy, nephropathy, and neuropathy. Nearly $40 \%$ of diabetic patients have the risk of developing diabetic nephropathy [9]. Diabetic nephropathy is characterized by an increased in albuminuria and a decreased in creatinine clearance. Statins are 3-hydroxy-3-methylglutaryl coenzyme A reductase inhibitors effective reduce both total and LDL cholesterol. Studies have found unequivocally that lowering LDL-C, particularly with statins, decreases the risk of cardiovascular deaths and events [10]. Recently years, there has been increasing interest in the role of statins in decreasing CIN risk in patients receiving contrast media [11-13]. This is owing to both their ability to anti-inflammatory and improve endothelial function properties, and their anti-apoptotic and anti-oxidant effects [14-16]. Rosuvastatin is a new generation of statin [14], which reduces levels of circulating LDL-C. In addition to its beneficial cholesterol lowering effects, rosuvastatin has been shown to protect against inflammatory, oxidant, and thrombotic effects, and may improve endothelial function. These effects of rosuvastatin have been translated into beneficial effects on atherosclerosis and have resulted in a significant reduction in cardiovascular events [17]. Our recent study reports that rosuvastatin reduces the risk of CIN in DM patients [18], and Leoncini et al. show that patients with renal dysfunction benefited from rosuvastatin therapy [19]. However, the mechanisms of rosuvastatin's reduction of CIN have not been reported. Furthermore, there is no evidence that rosuvastatin simultaneously attenuates inflammation, apoptosis or oxidation in vivo, each of which is prominent in CIN in the setting of diabetes mellitus. Therefore, the aim of the current study was to evaluate the anti-inflammatory, anti-apoptotic and anti-oxidant effects of rosuvastatin on CIN in diabetic rats.

\section{Material and methods}

Animals

Male Wistar rats (350-400 g) obtained from the Central Animal House of the General Hospital of Shenyang Military Region. Ethics was given by the Ethics Committee of the General Hospital of Shenyang Military Region. The experimental and animal care procedures were approved by the Institutional Animal Care and Use Committee of the General Hospital of Shenyang Military Region. The investigation conformed to the Guide for the Care and Use of Laboratory Animals published by the US National Institutes of Health.

\section{Induction of diabetes}

After $12 \mathrm{~h}$ of fasting, streptozotocin $(60 \mathrm{mg} / \mathrm{kg}$,Sigma, St. Louis, MO) was injected into the tail vein. After $24 \mathrm{~h}$, blood glucose levels over $250 \mathrm{mg} / \mathrm{dl}$ were considered diabetic. Diabetic state was confirmed by testing blood glucose levels on a daily basis.

\section{Rosuvatatin-treatment}

Rosuvastatin was orally administered at a dose of $10 \mathrm{mg} /$ $\mathrm{kg} /$ day by oral gavage for 5 consecutive days (days 1 to 5 ). The dose of rosuvastatin was decided according to Bae et al. [20].

\section{Induction of nephropathy}

CIN was induced by a single intravenous injection of indomethacin $(10 \mathrm{mg} / \mathrm{kg})$, double doses of N-nitro-Larginine methyl ester $(10 \mathrm{mg} / \mathrm{kg}$, twice at 15 and $30 \mathrm{~min}$ ) and a single dose of meglumine amidotrizoate 60\% (6 ml/kg; Urovist-Angiographin, Schering AG, Germany), according to Kedrah et al. [21].

\section{Animal grouping and experimental work}

Thirty-two male diabetic rats were allocated randomly to the following 4 equal groups $(\mathrm{n}=8 /$ group): diabetic group (D), diabetic + contrast media (DCM), diabetic + rosuvastatin (DR), diabetic + rosuvastatin + contrast media (DRCM). Another 8 healthy male rats + contrast media served as the non-diabetic rat control (NDCM). All the experimental groups were allowed to recover for $24 \mathrm{~h}$ in 
metabolic cages before being sacrificed on the day 6 . Rats were sacrificed by light ethyl ether anesthesia. Blood was collected by heart puncture, and we separated serum for renal function testing. The kidneys were removed for both biochemical and histopathological investigations.

\section{Determination of creatinine in serum and urine}

Serum samples were analyzed for biochemical parameters within $24 \mathrm{~h}$. Urine samples were also collected and analyzed. Concentrations of creatinine and urea in both serum and urine were analyzed as indicators of injured glomerular function. Creatinine clearance $(\mathrm{ml} / \mathrm{min})$ was calculated according to the formula: UV/P $(\mathrm{U}=$ creatinine concentration in urine $(\mathrm{mg} / \mathrm{dl}), \mathrm{V}=$ urine volume per $\min (\mathrm{ml} / \mathrm{min})$ and $\mathrm{P}=$ serum creatinine $(\mathrm{mg} / \mathrm{dl}))$. Fractional excretion of sodium (FENa) was calculated by formula (urine sodium/serum sodium $) \times($ serum creatinine/urine creatinine) $\times 100$.

\section{Inflammatory parameters}

Serum concentrations of interleukin-6 (IL-6) and tumor necrosis factor-alpha (TNF- $\nabla$ ) were analyzed by enzymelinked immunosorbent assay (ELISA) kits (R\&D Systems, USA) according to the manufacturer's instructions.

\section{Determination of biomarkers of oxidative stress}

The thiobarbiturates (TBARS) were determined according to Toprak et al. [22]. Levels of malondialdehyde (MDA) were measured using a spectrophotometric method. Sample absorbance was assayed at $532 \mathrm{~nm}$ and calculated by the absorbance of a standard. Thiol levels were measured using a method based on the thiol-disulphide interchange reaction between thiols and 5, 5'-dithio-bis-(2-nitrobenzoic acid). The serum protein carbonyl content (PCC) were analyzed according to Reznick AZ al.[23].

\section{Measurement levels of total nitrite/nitrate}

Nitrite and nitrate, the stable metabolic products of kidney tissues nitric oxide (NO), were measured by the Griess reaction for the simultaneous evaluation of nitrite and nitrate concentrations [24].

\section{Western blotting}

The renal tissue was homogenized in lysis buffer (pH 7.5, containing $300 \mathrm{mM} \mathrm{NaCl}, 50 \mathrm{mM}$ Tris-Cl, $0.5 \%$ Triton X-100, protease-inhibitor) and incubated at $4{ }^{\circ} \mathrm{C}$ for $30 \mathrm{~min}$. The lysates were centrifuged at $15,000 \mathrm{rpm}$ for $20 \mathrm{~min}$ at $4^{\circ} \mathrm{C}$. Concentrations of protein were determined by Bradford protein assay reagent (Bio-Rad, USA), and $30 \mathrm{~g}$ proteins were loaded onto 10\% SDS/PAGE. The gels were transferred to a nitrocellulose membrane and reacted with each antibody. Antibodies against phospho-p38, total-p38, cleaved capase- 3 and total caspase- 3 were obtained from Santa Cruz Biotechnology. Antibodies against $\beta$-actin, Bax, and Bcl-2 were obtained from Cell Signaling Technology. The ECL Western Blotting System was obtained from Amersham Biosciences.

\section{Histopathological investigation}

Kidneys were removed for histological analysis under a light microscope. Renal specimens from the used experimental groups were removed and immediately fixed in 10\% phosphate buffered formalin ( $\mathrm{pH}$ 7.4) for 24 hours, followed by dehydrating in ascending grades of ethyl alcohol, cleared in xylene and mounting in molting paraplast $58-62 \mathrm{C}^{\circ}$. Five $\mu \mathrm{m}$ thick were cut and stained with hematoxylin/ eosin. The criteria of injury and necrosis were analyzed semi-quantitatively method according to Ahmad [25]. Briefly, method of pathological score were as follows: $0=$ no damage; $1=$ minimal injury; $2=$ moderate injury; $3=$ intermediate injury; $4=$ severe injury; $5=$ very severe injury.

\section{TUNEL assay}

The assay was determine by a TUNEL detection kit by the manufacturer's instructions (Cell Signaling Technology, USA). Briefly, kidney samples were cut to $5 \mu \mathrm{m}$ sections and incubated with $15 \mu \mathrm{g} / \mathrm{ml}$ proteinase $\mathrm{K}$ for $10 \mathrm{~min}$ and then washed with PBS. Sections were immersed in terminal deoxynucleotidyltransferase and biotinylated dUTP in TdT buffer for $90 \mathrm{~min}$. The sections were incubated with anti-horseradish peroxidase-conjugated antibody at room temperature for $30 \mathrm{~min}$, and the resulting signals were visualized with diaminobenzidine. TUNEL-positive tubular cell numbers were counted at random in 20 nonoverlapping cortical fields under $200 \times$ magnification.

\section{Statistical analysis}

Data are expressed as mean \pm SD. Analyses were performed with SPSS 13.0. Group comparisons were evaluated by ANOVA followed by Tukey's test. Within-subject comparisons of continuous variables were carried out by a paired $t$-test. $\mathrm{P}$ value of $<0.05$ was considered statistically significant.

\section{Results}

\section{Biochemical parameters}

Levels of serum creatinine were notably increased in the DCM group compared with the NDCM, D or DR groups on day $6(\mathrm{P}<0.01)$. Treatment with rosuvastatin significantly decreased serum creatinine levels (DRCM vs DCM, $\mathrm{P}<0.01$ ) (Table 1), indicative of rosuvastatin protection against $\mathrm{CIN}$ in this model. On day 6 , creatinine clearance was notably lower in group DCM compare with groups NDCM, D, and DR $(\mathrm{P}<0.01)$. Levels were increased notably in group DRCM than in group DCM $(P<0.01)$. There were no differences in either levels of BUN or FENa among the groups. Levels of 
Table 1 Renal functional parameters in the study groups (mean \pm SD)

\begin{tabular}{llllll}
\hline & NDCM $(\mathbf{n}=\mathbf{8})$ & $\mathbf{D}(\mathbf{n}=\mathbf{8})$ & DR $(\mathbf{n}=\mathbf{8})$ & DCM $(\mathbf{n}=\mathbf{8})$ & DRCM $(\mathbf{n}=\mathbf{8})$ \\
\hline Serum creatinine $(\mathrm{mg} / \mathrm{dl})$ & $0.56 \pm 0.05 \#$ & $0.36 \pm 0.03$ & $0.38 \pm 0.03$ & $0.89 \pm 0.06^{*}$ & $0.42 \pm 0.04+$ \\
Serum BUN $(\mathrm{mg} / \mathrm{dl})$ & $14.98 \pm 1.62$ & $15.23 \pm 1.32$ & $16.26 \pm 1.48$ & $16.38 \pm 1.93$ & $16.45 \pm 1.53$ \\
Creatinine clearance $(\mathrm{ml} / \mathrm{min})$ & $1.53 \pm 0.18 \#$ & $2.68 \pm 0.25$ & $2.59 \pm 0.24$ & $1.08 \pm 0.09^{*}$ & $1.98 \pm 0.22+$ \\
FENa (\%) & $0.32 \pm 0.15$ & $0.29 \pm 0.10$ & $0.28 \pm 0.09$ & $0.31 \pm 0.14$ & $0.33 \pm 0.13$ \\
Urine microprotein $(\mathrm{mg} / \mathrm{dl})$ & $70.2 \pm 22.1 \#$ & $45.2 \pm 11.3$ & $38.6 \pm 14.3$ & $108.5 \pm 23.4^{*}$ & $69.3 \pm 18.2 \#$ \\
\hline
\end{tabular}

NDCM: non-diabetic rats + contrast media, D: diabetic group, DCM: diabetic rats treat + contrast media, DR: diabetic rats + rosuvastatin, DRCM: diabetic rats + rosuvastatin + contrast media.

${ }^{*} \mathrm{P}<0.01$ vs NDCM, D, D R and DRCM; $+\mathrm{P}<0.05$ vs NDCM, D and $\mathrm{DR}, \# \mathrm{P}<0.05$ vs $\mathrm{D}, \mathrm{DR}$.

urine microprotein were notably higher in group DCM compare with groups NDCM, D, DR and DRCM On day $6(\mathrm{P}<0.01)$. Additionally, levels of Urine microprotein were notably higher in group NDCM than in groups D and DR $(\mathrm{P}<0.05)$ (Table 1).

\section{Renal nitric oxide production}

From Table 2, kidney nitrite levels was notably decreased in the DCM group than in group $\mathrm{D}(\mathrm{P}<0.01)$. Additionally, levels of kidney nitrite in group DCM were notably decreased compared with those in groups NDCM, DR and DRCM $(\mathrm{P}<0.01)$. Levels of kidney nitrite in DRCM were increased than those in NDCM $(\mathrm{P}<0.01)$. Additionally, levels of the kidney nitrite in group NDCM were lower compared with groups D and DR $(\mathrm{P}<0.05)$.

\section{Oxidative stress markers}

As shown in Table 3, we had not found any difference between the DR group and the D group in terms of serum PCC, MDA, thiol and kidney TBARS levels. The kidney TBARS level was notably increased in DCM group than in D group and DR group $(\mathrm{P}<0.01)$. Additionally, when the DCM group was compared to both the NDCM and DRCM groups, kidney TBARS was notably higher in the DCM group $(\mathrm{P}<0.01)$. In group NDCM, kidney TBARS was notably increased than in groups D and DR $(\mathrm{P}<0.05)$. Serum MDA was notably increased in group DCM than in groups D and DR $(\mathrm{P}<0.01)$. The serum MDA level was notably lower in the DRCM group than in the DCM group $(\mathrm{P}<0.01)$, but it was still higher than the levels in both group D and group DR $(\mathrm{P}<0.05)$ (Table 3$)$. In group NDCM, kidney TBARS was notably increased than in groups $\mathrm{D}, \mathrm{DR}$ and DRCM $(\mathrm{P}<0.05)$. When the DCM group was compared with group D and group DR, serum thiol levels were notably decreased in the DCM group $(\mathrm{P}<0.01)$. However, in the DRCM group, serum thiol levels were notably higher than DCM group $(\mathrm{P}<0.05)$. In group NDCM, levels of serum thiol were notably increased than in groups $D, D R$ and DRCM $(\mathrm{P}<0.05)$. The serum PCC level was notably increased in DCM group than in D group and DR group $(\mathrm{P}<0.01)$. In the DRCM group, serum PCC levels were notably lower compared to the DCM group $(\mathrm{P}<0.01)$. In group NDCM, levels of serum PCC were notably higher than in groups $\mathrm{D}, \mathrm{DR}$ and DRCM $(\mathrm{P}<0.05)$ and decreased than in group DCM $(\mathrm{P}<0.01)$.

\section{Inflammatory parameters}

As shown in Table 4, there was not any significant difference between the DR group and D group in terms of serum IL- 6 and TNF- $\alpha$ levels. When compared with either the D or DR group, the DCM group had higher serum levels of both IL-6 $(\mathrm{P}<0.01)$ and TNF- $\alpha(\mathrm{P}<0.01)$. However, when compared to the DCM group, treatment with rosuvastatin reduced the CM-induced increase in both serum IL-6 $(\mathrm{P}<0.05)$ and TNF- $\alpha$ levels $(\mathrm{P}<0.05)$. In group NDCM, serum IL-6 and TNF- $\alpha$ levels were notably lower than in group DCM $(\mathrm{P}<0.05)$.

\section{Renal histopathology}

As shown in Figure 1, in group NDCM, histological scores were notably decreased than in group DCM $(\mathrm{P}<0.01)$. However, injury was found to be more severe in than DCM group than in groups $\mathrm{D}$ and $\mathrm{DR}(\mathrm{P}<0.01)$, but the degree of injury was less severe in DRCM group, compared with DCM group $(\mathrm{P}<0.05)$, suggesting that rosuvastatin therapy significantly protected the kidney from the contrast media.

Table 2 Nitric oxide and nitrite/nitrate levels ( $\mathrm{nmol} / \mathrm{mg}$ protein) in the kidneys (mean \pm SD)

\begin{tabular}{llllll}
\hline & NDCM $(\mathbf{n}=\mathbf{8})$ & $\mathbf{D}(\mathbf{n}=\mathbf{8})$ & DR $(\mathbf{n}=\mathbf{8})$ & DCM $(\mathbf{n}=\mathbf{8})$ & DRCM $(\mathbf{n}=\mathbf{8})$ \\
\hline Nitrite & $0.038 \pm 0.003 \#$ & $0.049 \pm 0.006$ & $0.052 \pm 0.007$ & $0.026 \pm 0.002^{*}$ & $0.048 \pm 0.004^{* *}$ \\
Nitrate & $6.543 \pm 0.721$ & $6.383 \pm 0.691$ & $6.430 \pm 0.683$ & $6.625 \pm 0.822$ & $6.831 \pm 0.760$ \\
Total nitrite/nitrate & $6.581 \pm 0.702$ & $6.432 \pm 0.721$ & $6.482 \pm 0.694$ & $6.651 \pm 0.831$ & $6.879 \pm 0.762$ \\
\hline
\end{tabular}

NDCM: non-diabetic rats + contrast media, D: diabetic group, DCM: diabetic rats + contrast media, DR: diabetic rats + rosuvastatin, DRCM: diabetic 
Table 3 Oxidative stress markers of the study groups (mean \pm SD)

\begin{tabular}{llllll}
\hline & NDCM $(\mathbf{n}=\mathbf{8})$ & $\mathbf{D}(\mathbf{n}=\mathbf{8})$ & DR $(\mathbf{n}=\mathbf{8})$ & DCM $(\mathbf{n}=\mathbf{8})$ & DRCM $(\mathbf{n}=\mathbf{8})$ \\
\hline Kidney TBARS $(\mathrm{nmol} / \mathrm{g})$ & $36.21 \pm 5.21 \#$ & $30.23 \pm 6.30$ & $29.38 \pm 5.38$ & $42.62 \pm 6.12^{*}$ & $32.26 \pm 4.28$ \\
Serum MDA $(\mu \mathrm{mol} / \mathrm{l})$ & $7.23 \pm 1.12 \#$ & $3.03 \pm 0.52$ & $3.18 \pm 0.61$ & $9.25 \pm 1.23^{*}$ & $4.56 \pm 0.78+$ \\
Serum Thiol $(\mu \mathrm{mol} / \mathrm{l})$ & $287.78 \pm 29.23 \#$ & $362.25 \pm 58.16$ & $343.16 \pm 62.11$ & $247.16 \pm 23.87^{*}$ & $346.19 \pm 30.18^{* *}$ \\
Serum PCC $(\mu \mathrm{mol} / \mathrm{l})$ & $10.11 \pm 1.34 \#$ & $7.68 \pm 1.21$ & $8.12 \pm 0.92$ & $14.23 \pm 1.73^{*}$ & $8.38 \pm 1.19^{* *}$ \\
\hline
\end{tabular}

NDCM: non-diabetic rats + contrast media, D: diabetic group, DCM: diabetic rats + contrast media, DR: diabetic rats + rosuvastatin, DRCM: diabetic rats + rosuvastatin + contrast media.

${ }^{*} \mathrm{P}<0.01$ vs NDCM, D, DR and DRCM; $+\mathrm{P}<0.05$ vs NDCM, D and DR; \# $<0.05$ vs $\mathrm{D}, \mathrm{DR} ;{ }^{* *} \mathrm{P}<0.05$ vs NDCM.

\section{Apoptosis}

As shown in Figure 2, TUNEL staining showed that DCM showed a more significant extent compared with either the D group or DR group. The percentage of apoptotic cells was lower in the DRCM group than in the DCM group $(\mathrm{P}<0.01)$. Additionally, the percentage of apoptotic cells was significantly higher in the DCM group than in the NDCM group $(\mathrm{P}<0.01)$.

Previous studies have suggested that contrast mediainduced apoptosis is mediated by activation of the p38 mitogen-activated protein kinase (MAPK) signal pathway [26]. As shown in Figure 3, the protein expression of phospho-p38 was notably increased in group DCM compared to groups $\mathrm{D}$ and $\mathrm{DR}(\mathrm{P}<0.01)$, and it was also higher in group DCM compared to group RCM $(\mathrm{P}<0.01)$. In NDCM group, the protein expression of phospho-p38 was notably decreased compared with the DCM group. To confirm the presence of apoptosis in CIN rats, we investigated the caspase- 3 substrate, Bax and Bcl-2 using Western blotting. The activation of caspase-3 was notably increased in DCM group compared to the NDCM, D and DR groups $(\mathrm{P}<0.01)$. Additionally the activation of caspase-3 levels was notably reduced in group DRCM than in the DCM group $(\mathrm{P}<0.01)$. The expression of the Bax/Bcl-2 ratio was notably increased in the DCM group than in D group and DR group $(\mathrm{P}<0.01)$. When the DCM group was compared with the NDCM and DRCM groups, the $\mathrm{Bax} / \mathrm{Bcl}-2$ ratio was notably increased in DCM group $(\mathrm{P}<0.01)$. In group NDCM, the expression of the $\mathrm{Bax} / \mathrm{Bcl}-2$ ratio was notably increased than in groups $\mathrm{D}$ and $\mathrm{DR}(\mathrm{P}<0.05)$.

\section{Discussion}

For the first time, we investigated the effects of rosuvastatin treatment, initiated 5 days before the administration of contrast media to induce $\mathrm{CIN}$ in diabetic rats. We demonstrated that rosuvastatin decreased oxidative damage, inflammatory responses, kidney injury and apoptosis. Our findings support that rosuvastatin decreased CIN in diabetic rats.

In recent years, statins have been found to reduce the risk of CIN in DM patients [27]. Rosuvastatin has potent anti-inflammatory properties: it increases nitric oxide synthetase bioavailability, and reduces oxidative stress independent of its cholesterol-lowering effect [14]. We recently reported that rosuvastatin significantly decreases the CIN risk in DM patients with CKD undergoing arterial contrast media injection [18]. In current study, we found that there was a significant increase in renal injury biomarkers, including serum creatinine and creatinine clearance, in the rats administration with contrast media. Pretreatment with rosuvastatin significantly reversed the effects of the contrast media on serum renal injury markers, as well as creatinine clearance.

Contrast media induces a decrease in the expression of NO [16,22]. Rosuvastatin and other statins improve endothelial function by increasing NO synthetase bioavailability and decreasing oxidative stress [14]. In current study, we found that a decrease in product of nitrite, were the cause of elevation in creatinine levels and of renal histopathological alteration. We also found that levels of kidney nitrite were notably increased in DRCM group compared with DCM group after treatment with rosuvastatin. This may explain why renal injury was less significant in group DRCM than in DCM.

Our results showed that pretreatment with rosuvastatin reversed CM-induced oxidative stress in rats. CIN pathophysiology research shows that this condition is most same with result of renal ischemia, oxidative injury and direct toxicity to tubular epithelial cells [5,28]. After using contrast media, reactive oxygen species cause and enhance lipid peroxidation and cytotoxic damage, suggesting that

Table 4 Inflammatory parameters in the study groups (mean \pm SD)

\begin{tabular}{|c|c|c|c|c|c|}
\hline & $\operatorname{NDCM}(n=8)$ & $D(n=8)$ & $\mathrm{DR}(\mathrm{n}=8)$ & $\operatorname{DCM}(n=8)$ & $\operatorname{DRCM}(n=8)$ \\
\hline IL-6 (pg/ml) & $11.28 \pm 1.45 \#$ & $7.63 \pm 0.93$ & $7.23 \pm 0.69$ & $15.14 \pm 1.23^{*}$ & $12.23 \pm 1.06 \#$ \\
\hline TNF-a (pg/ml) & $36.35 \pm 5.67 \#$ & $27.12 \pm 2.31$ & $25.34 \pm 2.15$ & $48.56 \pm 5.23^{*}$ & $37.25 \pm 4.12 \#$ \\
\hline
\end{tabular}

NDCM: non-diabetic rats + contrast media, D: diabetic group, DCM: diabetic rats + contrast media, DR: diabetic rats + rosuvastatin, DRCM: diabetic rats + rosuvastatin + contrast media

${ }^{*} \mathrm{P}<0.01$ vs NDCM, D, DR and DRCM; \# $\mathrm{P}<0.05$ vs $\mathrm{D}$ and DR. 


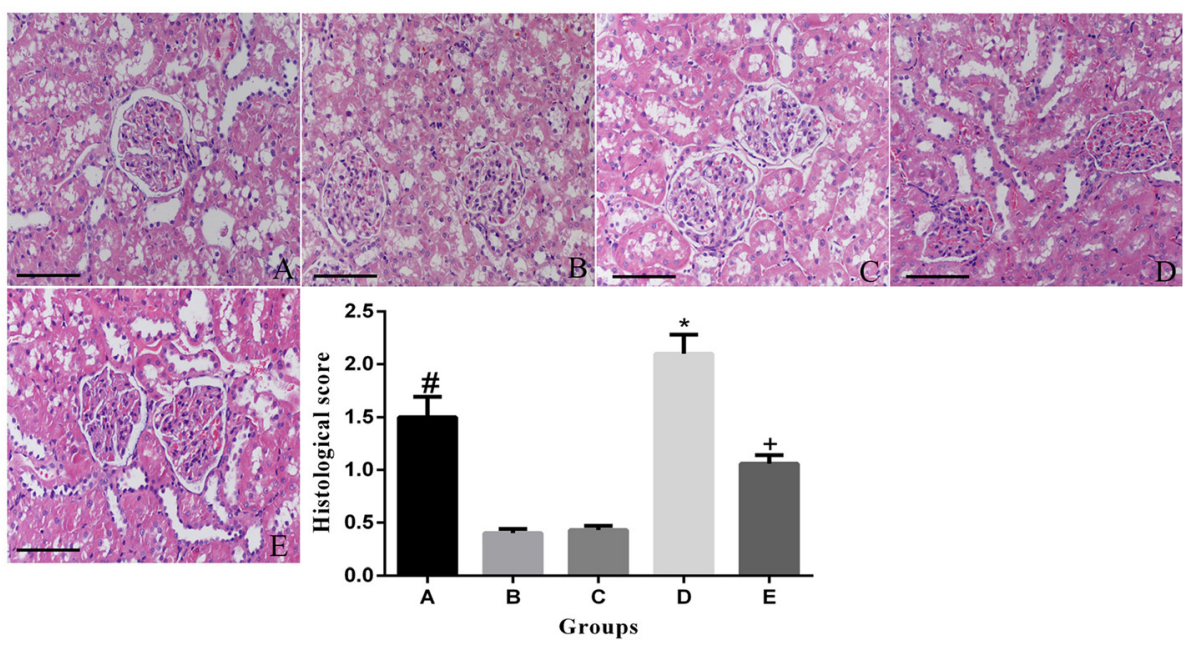

Figure 1 Light microscopy of renal tissue from rats stained with hematoxylin and eosin. A: non-diabetic rats + contrast media group, B: diabetic group, $\mathbf{C}$ : diabetic + contrast media group, D: diabetic + rosuvastatin group, E: diabetic + rosuvastatin + contrast media group. ${ }^{*} P<0.01$ vs $A, B, D$ and $E_{i}+P<0.05$ vs $A, B$ and $D ; \# P<0.05$ vs B and $D$. Scale bar: $50 \mu \mathrm{m}$.

oxidative injury is a major risk factor in the CIN pathogenesis [29]. A body of evidence has demonstrated that rosuvastatin has distinctive anti-inflammatory properties, improving oxidative injury and reducing oxidant and free radical generation [14,30-33]. We speculated that rosuvastatin decreases the contrast-induced explosion of serum MDA, PCC and renal TBARS and increases serum thiol levels, therefore ameliorating the renal histopathological findings in DRCM group.
Although the pathogenesis of CIN is still not completely understood, there is mounting evidence to support the critical role of inflammation in the pathogenesis of CIN $[28,34]$. TNF- $\alpha$ is a cascade-inducing pro-inflammatory cytokine that further recruits numerous mediators associated with endothelial and tissue injury. In the mouse model of nephrotoxicity, TNF- $\alpha$ was proven to play a central role in the activation of the inflammatory cytokine response [35]. IL-6 elicits many biological effects, one of which is

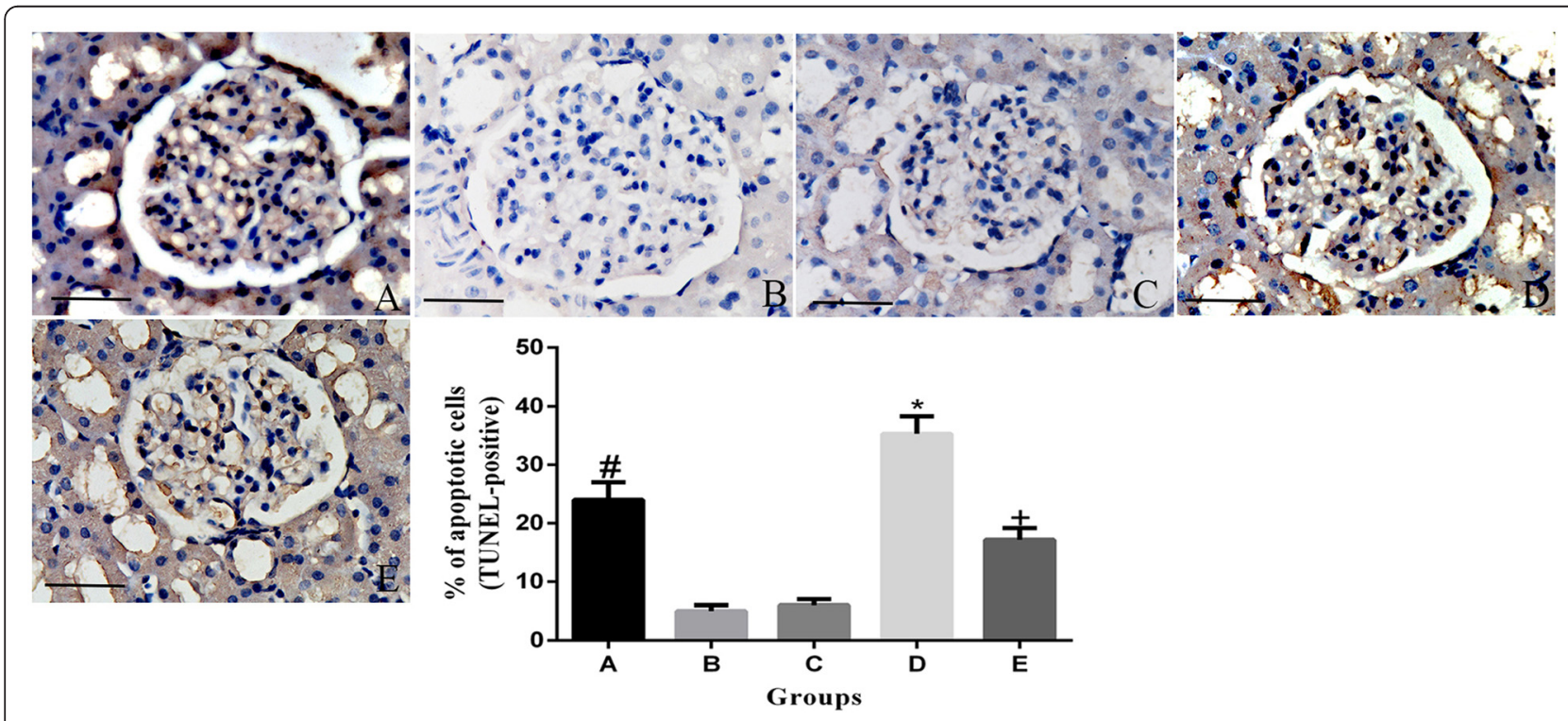

Figure 2 Rosuvastatin inhibited contrast media-induced renal cell apoptosis. Contrast media increases TUNEL-positive renal tubular cell number, whereas rosuvastatin pretreatment prevented contrast media-induced apoptosis. $\mathbf{A}$ : non-diabetic rats + contrast media group, $\mathbf{B}$ : diabetic group, C: diabetic + contrast media group, D: diabetic + rosuvastatin group, E: diabetic + rosuvastatin + contrast media group. ${ }^{*}$ P $<0.01$ vs A, B, D and $E_{;}+P<0.05$ vs $A, B$ and $D ; \# P<0.05$ vs B, D. Scale bar: $20 \mu \mathrm{m}$. 

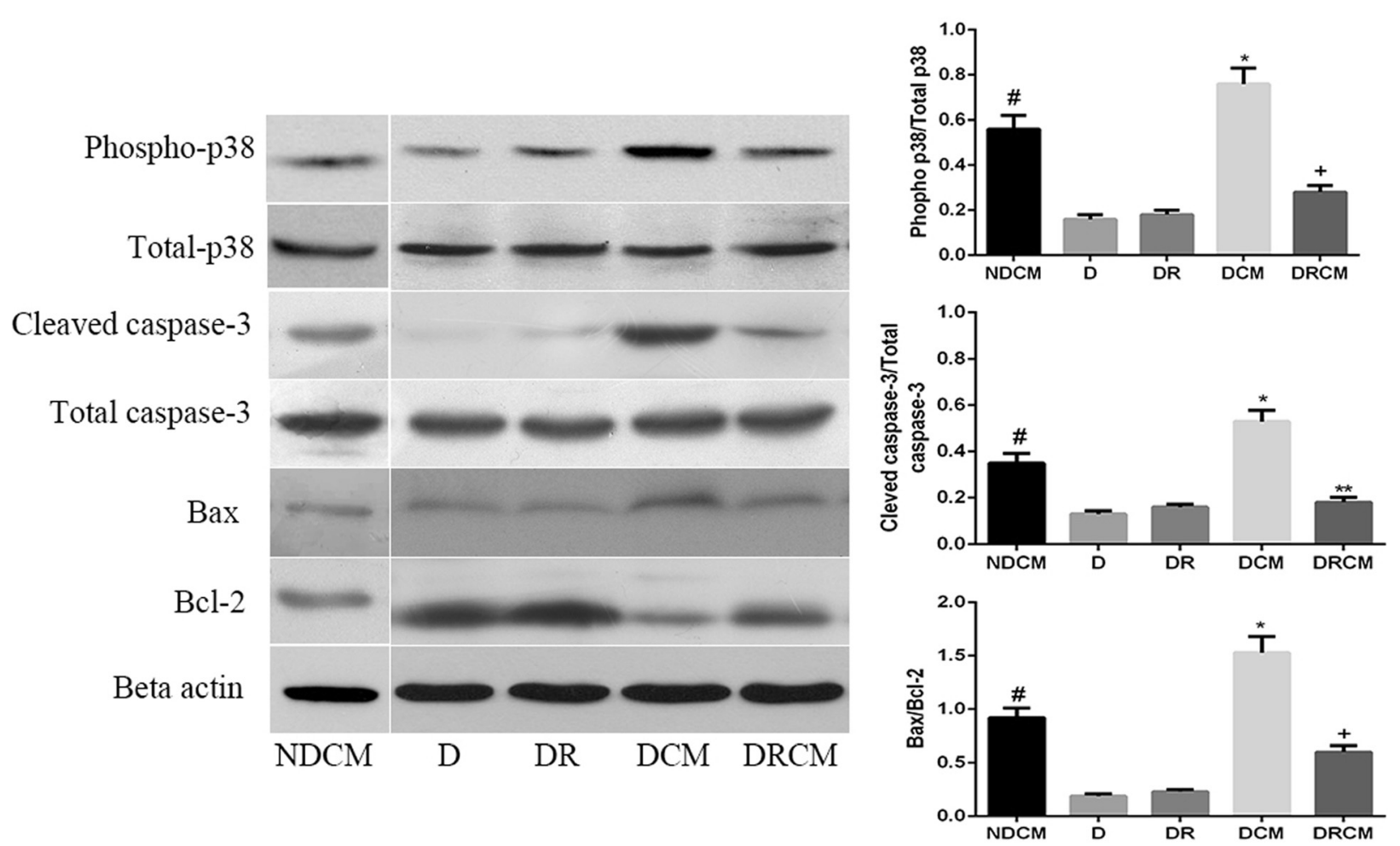

Figure 3 Rosuvastatin decreased phospho-p38, cleaved caspase-3 and Bax/Bcl-2 protein expression by Western blotting. Beta-Actin was used as a loading control. NDCM: non-diabetic rats + contrast media, D: diabetic group, DCM: diabetic + contrast media group, DR: diabetic + rosuvastatin group, DRCM: diabetic + rosuvastatin + contrast media group. ${ }^{*} \mathrm{P}<0.01$ vs NDCM, D, DR and DRCM; +P $<0.05$ vs NDCM, D and $\mathrm{DR} ; \# \mathrm{P}<0.05$ vs $\mathrm{D}$ and $\mathrm{DR}$.

the initiation of the inflammatory response [36]. It is synthesized in response to proinflammatory signals, and its production is also a common response to tissue injury and organ failure [37]. Contrast media treatment was followed by an increase levels of IL-6 in the kidney [38]. IL-6 and TNF- $\alpha$ are associated with CIN risk and poor long-term renal outcome after PCI [35,39]. Many Studies have showed that rosuvastatin may be as a therapeutic option in renal diseases that are characterized by preventing inflammation, apoptosis and fibrosis [40-43]. Our results showed that treatment with rosuvastatin reduced expression of serum IL-6 and TNF- $\alpha$. Therefor rosuvastatin likely protects the kidney from CIN through the inhibition of renal inflammation. P 38 are also capable to enhanced IL-6 and TNF- $\alpha$ expression [35], our result confirm previous finding, and that rosuvastatin was able to prevent this effect.

Previous studies demonstrated that intrinsic or mitochondrial pathway involve in $\mathrm{CM}$ induces renal cells apoptosis [44]. In current study, we found that treatment with rosuvastatin prevented (1) CM-mediated caspase-3 activation, (2) CM-induced increase of ratio of $\mathrm{Bax} / \mathrm{Bcl}-2$, (3) CM-induced an increase in TUNEL staining cells, indicating that rosuvastatin prevents apoptosis in CIN.
Other works have suggested that contrast media-induced apoptosis can be mediated by activation of the p38 MAPK in vitro and in vivo $[26,45]$. Current study showed that the rosuvastatin reduce CIN by suppression of apoptotic may be through inhibition of p38 MAPK pathways.

\section{Conclusions}

Rosuvastatin attenuates contrast media-induced nephropathy by modulation of nitric oxide, inflammatory responses, oxidative stress and apoptotic processes, including p38 MAPK pathways. Our findings show that rosuvastatin may have an important role in preventing CIN.

\section{Abbreviations \\ CIN: Contrast-induced nephropathy; TBARS: Kidney thiobarbituric acid-reacting substances; MDA: Malondialdehyde; PCC: Protein carbonyl content; DM: Diabetes mellitus; LDL-C: Low-density lipoprotein cholesterol; FENa: Fractional excretion of sodium; IL-6: Interleukin-6; TNF-a: Tumor necrosis factor-alpha; ELISA: Enzyme-linked immunosorbent assay; NO: Nitric oxide; MAPK: Mitogen-activated protein kinase.}

Competing interest

The authors declare that they have no competing interests. 


\section{Authors' contributions}

JD Study design, animal experiments, manuscript writing and revising; GJ Animal experiments, CY Animal experiments, YL Study design, manuscript revision, QJ Study design, manuscript revision, YH Study design, animal experiments, manuscript writing. All authors read and approved the final manuscript.

\section{Received: 28 September 2014 Accepted: 22 January 2015 Published online: 12 February 2015}

\section{References}

1. Asif A, Epstein M. Prevention of radiocontrast-induced nephropathy. Am J Kidney Dis. 2004;44:12-24.

2. Sterling KA, Tehrani T, Rudnick MR. Clinical significance and preventive strategies for contrast-induced nephropathy. Curr Opin Nephrol Hypertens. 2008;17:616-23.

3. Rundback JH, Nahl D, Yoo V. Contrast-induced nephropathy. J Vasc Surg. 2011;54:575-9.

4. Mehran R, Aymong ED, Nikolsky E, Lasic Z, lakovou I, Fahy M, et al. A simple risk score for prediction of contrast-induced nephropathy after percutaneous coronary intervention: development and initial validation. J Am Coll Cardiol. 2004:44:1393-9.

5. Zaytseva NV, Shamkhalova MS, Shestakova MV, Matskeplishvili ST, Tugeeva EF, Buziashvili UI, et al. Contrast-induced nephropathy in patients with type 2 diabetes during coronary angiography: risk-factors and prognostic value. Diabetes Res Clin Pract. 2009;86 Suppl 1:S63-69.

6. Goldenberg I, Matetzky S. Nephropathy induced by contrast media: pathogenesis, risk factors and preventive strategies. CMAJ. 2005;172:1461-71.

7. Heyman SN, Rosenberger C, Rosen S, Khamaisi M. Why is diabetes mellitus a risk factor for contrast-induced nephropathy? BioMed Res Int. 2013;2013:123589.

8. Chen SC, Tseng CH. Dyslipidemia, kidney disease, and cardiovascular disease in diabetic patients. Rev Diabet Stud. 2013;10:88-100.

9. Calvin AD, Misra S, Pflueger A. Contrast-induced acute kidney injury and diabetic nephropathy. Nat Rev Nephrol. 2010;6:679-88.

10. Heart Protection Study Collaborative G. MRC/BHF Heart Protection Study of cholesterol lowering with simvastatin in 20,536 high-risk individuals: a randomised placebo-controlled trial. Lancet. 2002;360:7-22.

11. Zhang $T$, Shen LH, Hu LH, He B. Statins for the prevention of contrast-induced nephropathy: a systematic review and meta-analysis. Am J Nephrol. 2011;33:344-51.

12. Zhou Y, Yuan WJ, Zhu N, Wang L. Short-term, high-dose statins in the prevention of contrast-induced nephropathy: a systematic review and meta-analysis. Clin Nephrol. 2011;76:475-83.

13. Pappy R, Stavrakis S, Hennebry TA, Abu-Fadel MS. Effect of statin therapy on contrast-induced nephropathy after coronary angiography: a meta-analysis. Int J Cardiol. 2011;151:348-53.

14. Luvai A, Mbagaya W, Hall AS, Barth JH. Rosuvastatin: a review of the pharmacology and clinical effectiveness in cardiovascular disease. Clin Med Insights Cardiol. 2012;6:17-33.

15. Quintavalle C, Fiore D, De Micco F, Visconti G, Focaccio A, Golia B, et al. Impact of a high loading dose of atorvastatin on contrast-induced acute kidney injury. Circulation. 2012;126:3008-16.

16. Al-Otaibi KE, Al Elaiwi AM, Tariq M, Al-Asmari AK. Simvastatin attenuates contrast-induced nephropathy through modulation of oxidative stress, proinflammatory myeloperoxidase, and nitric oxide. Oxidative Med Cell Longev. 2012;2012:831748.

17. Hu M, Tomlinson B. Current perspectives on rosuvastatin. Integr Blood Press Control. 2013;6:15-25.

18. Han Y, Zhu G, Han L, Hou F, Huang W, Liu H, et al. Short-term rosuvastatin therapy for prevention of contrast-induced acute kidney injury in patients with diabetes and chronic kidney disease. J Am Coll Cardiol. 2014;63:62-70.

19. Leoncini M, Toso A, Maioli M, Tropeano F, Villani S, Bellandi F. Early high-dose rosuvastatin for contrast-induced nephropathy prevention in acute coronary syndrome: Results from the PRATO-ACS Study (Protective Effect of Rosuvastatin and Antiplatelet Therapy On contrast-induced acute kidney injury and myocardial damage in patients with Acute Coronary Syndrome). J Am Coll Cardiol. 2014:63:71-9.

20. Bae EH, Kim IJ, Park JW, Ma SK, Lee JU, Kim SW. Renoprotective effect of rosuvastatin in DOCA-salt hypertensive rats. Nephrol Dial Transplant. 2010;25:1051-9.
21. Kedrah AE, Ari E, Alahdab Y, Gul CB, Macunluoglu B, Atakan A, et al. Effect of the direct renin inhibitor aliskiren in the prevention of experimental contrast-induced nephropathy in the rat. Kidney Blood Press Res. 2012;35:425-30.

22. Toprak O, Cirit M, Tanrisev M, Yazici C, Canoz O, Sipahioglu M, et al. Preventive effect of nebivolol on contrast-induced nephropathy in rats. Nephrology, dialysis, transplantation : official publication of the European Dialysis and Transplant Association - European Renal Association. 2008;23:853-9.

23. Reznick $A Z$, Packer $L$. Oxidative damage to proteins: spectrophotometric method for carbonyl assay. Methods Enzymol. 1994;233:357-63.

24. Moshage H, Kok B, Huizenga JR, Jansen PL. Nitrite and nitrate determinations in plasma: a critical evaluation. Clin Chem. 1995;41:892-6.

25. Ahmad A, Mondello S, Di Paola R, Mazzon E, Esposito E, Catania MA, et al. Protective effect of apocynin, a NADPH-oxidase inhibitor, against contrast-induced nephropathy in the diabetic rats: a comparison with n-acetylcysteine. Eur J Pharmacol. 2012;674:397-406.

26. Gong X, Celsi G, Carlsson K, Norgren S, Chen M. N-acetylcysteine amide protects renal proximal tubular epithelial cells against iohexol-induced apoptosis by blocking p38 MAPK and iNOS signaling. Am J Nephrol. 2010;31:178-88.

27. Alpert MA. Do statins reduce the risk of contrast-induced acute kidney injury in patients undergoing coronary angiography or percutaneous coronary interventions? J Am Coll Cardiol. 2014;63:80-2.

28. Buyuklu M, Mehmet Kandemir F, Ozkaraca M, Set T, Murat Bakirci E, Topal E. Protective effect of curcumin against contrast induced nephropathy in rat kidney: what is happening to oxidative stress, inflammation, autophagy and apoptosis? Eur Rev Med Pharmacol Sci. 2014;18:461-70.

29. Heyman SN, Rosen S, Khamaisi M, Idee JM, Rosenberger C. Reactive oxygen species and the pathogenesis of radiocontrast-induced nephropathy. Investig Radiol. 2010;45:188-95.

30. Holvoet P. Relations between metabolic syndrome, oxidative stress and inflammation and cardiovascular disease. Verh K Acad Geneeskd Belg. 2008;70:193-219.

31. Habibi J, Whaley-Connell A, Qazi MA, Hayden MR, Cooper SA, Tramontano A, et al. Rosuvastatin, a 3-hydroxy-3-methylglutaryl coenzyme a reductase inhibitor, decreases cardiac oxidative stress and remodeling in Ren2 transgenic rats. Endocrinology. 2007;148:2181-8.

32. Sicard P, Delemasure S, Korandji C, Segueira-Le Grand A, Lauzier B, Guilland JC, et al. Anti-hypertensive effects of Rosuvastatin are associated with decreased inflammation and oxidative stress markers in hypertensive rats. Free Radic Res. 2008:42:226-36.

33. Kim YH, Park SM, Kim M, Kim SH, Lim SY, Ahn JC, et al. Cardioprotective effects of rosuvastatin and carvedilol on delayed cardiotoxicity of doxorubicin in rats. Toxicol Mech Methods. 2012;22:488-98.

34. Jorgensen AL. Contrast-induced nephropathy: pathophysiology and preventive strategies. Crit Care Nurse. 2013;33:37-46.

35. Chang CF, Lu TM, Yang WC, Lin SJ, Lin CC, Chung MY. Gene polymorphisms of interleukin-10 and tumor necrosis factor-alpha are associated with contrast-induced nephropathy. Am J Nephrol. 2013;37:110-7.

36. Lauta VM. Interleukin- 6 and the network of several cytokines in multiple myeloma: an overview of clinical and experimental data. Cytokine. 2001;16:79-86.

37. Sekiyama KD, Yoshiba M, Thomson AW. Circulating proinflammatory cytokines (IL-1 beta, TNF-alpha, and IL-6) and IL-1 receptor antagonist (IL-1Ra) in fulminant hepatic failure and acute hepatitis. Clin Exp Immunol. 1994;98:71-7.

38. Machado RA, Constantino Lde S, Tomasi CD, Rojas HA, Vuolo FS, Vitto MF, et al. Sodium butyrate decreases the activation of NF-kappaB reducing inflammation and oxidative damage in the kidney of rats subjected to contrast-induced nephropathy. Nephrol Dial Transplant. 2012;27:3136-40.

39. Hudzik B, Szkodzinski J, Danikiewicz A, Romanowski W, Lekston A, Polonski $L$, et al. Serum interleukin-6 concentration predicts contrast-induced nephropathy in patients undergoing percutaneous coronary intervention. Eur Cytokine Netw. 2010;21:129-35.

40. Nam HK, Lee SJ, Kim MH, Rho JH, Son YK, Lee SM, et al. Rosuvastatin attenuates inflammation, apoptosis and fibrosis in a rat model of cyclosporine-induced nephropathy. Am J Nephrol. 2013;37:7-15.

41. Yen CH, Sun CK, Leu S, Wallace CG, Lin YC, Chang LT, et al. Continuing exposure to low-dose nonylphenol aggravates adenine-induced chronic 
renal dysfunction and role of rosuvastatin therapy. J Transl Med. 2012;10:147.

42. Girardi JM, Farias RE, Ferreira AP, Raposo NR. Rosuvastatin prevents proteinuria and renal inflammation in nitric oxide-deficient rats. Clinics. 2011;66:1457-62.

43. Gianella A, Nobili E, Abbate M, Zoja C, Gelosa P, Mussoni L, et al. Rosuvastatin treatment prevents progressive kidney inflammation and fibrosis in stroke-prone rats. Am J Pathol. 2007;170:1165-77.

44. Quintavalle C, Brenca M, De Micco F, Fiore D, Romano S, Romano MF, et al. In vivo and in vitro assessment of pathways involved in contrast media-induced renal cells apoptosis. Cell Death Dis. 2011;2:e155.

45. Gong X, Wang Q, Tang X, Wang Y, Fu D, Lu H, et al. Tetramethylpyrazine prevents contrast-induced nephropathy by inhibiting p38 MAPK and FoxO1 signaling pathways. Am J Nephrol. 2013;37:199-207.

\section{Submit your next manuscript to BioMed Central and take full advantage of:}

- Convenient online submission

- Thorough peer review

- No space constraints or color figure charges

- Immediate publication on acceptance

- Inclusion in PubMed, CAS, Scopus and Google Scholar

- Research which is freely available for redistribution 